Article

\title{
Participatory Design of Multi-Use Platforms at Sea
}

\author{
Sander van den Burg ${ }^{1, *}$, Marian Stuiver ${ }^{2}$, Jenny Norrman ${ }^{3}$, Rita Garção ${ }^{3}$, Tore Söderqvist ${ }^{4}$, \\ Christine Röckmann ${ }^{5}$, Jan-Joost Schouten ${ }^{6}$, Ole Petersen ${ }^{7}$, Raul Guanche García ${ }^{8}$, \\ Pedro Diaz-Simal ${ }^{8}$, Mark de Bel ${ }^{9}$, Lucía Meneses Aja ${ }^{8}$, Fabio Zagonari ${ }^{10}$, Barbara Zanuttigh ${ }^{11}$, \\ Javier Sarmiento ${ }^{8}$, Amerissa Giannouli ${ }^{12,14}$ and Phoebe Koundouri ${ }^{12,13,14}$
}

1 LEI Wageningen UR, P.O. Box 29703, 2502 LS The Hague, The Netherlands

2 Alterra Wageningen UR, P.O. Box 47,6700 AA Wageningen, The Netherlands; marian.stuiver@wur.nl

3 Department of Civil and Environmental Engineering, Chalmers University of Technology,

SE-412 96 Göteborg, Sweden; jenny.norrman@chalmers.se (J.N.); rita.garcao@gmail.com (R.G.)

4 Enveco Environmental Economics Consultancy, Måsholmsgränd 3, SE-127 48 Skärholmen, Sweden; tore@enveco.se

5 Institute for Marine Resources \& Ecosystem Studies (IMARES), Wageningen UR, PO Box 57, 1780 AB Den Helder, The Netherlands; christine.rockmann@wur.nl

6 Department Harbour, Coastal and Offshore Engineering, Deltares, P.O. Box 177, 2600 MH Delft, The Netherlands; janjoostschouten@deltares.nl (J.-J.S.)

7 DHI, Agernalle 5, 2970 Horsholm, Denmark; osp@dhigroup.com

8 Environmental Hydraulics Institute, IH Cantabria, University of Cantabria, c/ Isabel Torres, 15 Santander, Spain; raul.guanche@unican.se (R.G.G.); pedro.diaz@unican.es (P.D.-S.); lucia.meneses@unican.es (L.M.A.); javier.sarmiento@unican.es (J.S.)

9 Department Water Resources and Delta Management, Deltares, P.O. Box 177, 2600 MH Delft, The Netherlands; mark.debel@deltares.nl

10 Department of Economics, University of Bologna, via Angherà 22, 47921 Rimini, Italy; fabio.zagonari@unibo.it

11 Department of Civil, Chemicals, Environmental and Materials Engineering, University of Bologna, Viale Risorgimento 2, 40136 Bologna, Italy; barbara.zanuttigh@unibo.it

12 School of Economics, Athens University of Economics and Business, 28is Oktovriou 76, 15125 Athens, Greece; amerissa.giannouli@icre8.eu (A.G.); phoebe.koundouri@icre8.eu (P.K.)

13 Grantham Institute, London School of Economics and Political Science, Houghton St, WC2A 2AE London, UK

14 International Centre for Research on the Environment and the Economy, Artemidos 6 \&Epidavrou, Marousi, 15125 Athens, Greece

* Correspondence: sander.vandenburg@wur.nl; Tel.: + 31-(0)-70-335-8129

Academic Editor: Vincenzo Torretta

Received: 7 December 2015; Accepted: 21 January 2016; Published: 29 January 2016

Abstract: European oceans are subject to rapid development. New activities such as aquaculture and ocean energy have gained importance. This triggers interest in "multi-use platforms at sea" (MUPS), i.e., areas at sea in which different activities are combined. MUPS are complex features with regards to technology, governance, and financial, socioeconomic, and environmental aspects. To identify realistic and sustainable solutions and designs for MUPS, the MERMAID project applied a participatory design process (PDP) involving a range of stakeholders representing companies, authorities, researchers, and NGOs. This paper evaluates if and how the participatory design process contributed to the design of multi-use platforms. It is based on interviews with the managers of the case study sites and a questionnaire administered to all stakeholders participating in the PDP workshops. Analyzing the four case studies, we conclude that the participatory design process has had a valuable contribution to the development of the four different designs of MUPS, even though the preconditions for carrying out a participatory design process differed between sites. In all four cases, the process has been beneficial in generating new and shared knowledge. It brought new design issues to the table and increased knowledge and understanding among the different stakeholders. 
Keywords: participatory design; multi-use platforms at sea; offshore wind; ocean energy; aquaculture

\section{Introduction}

European oceans are subject to rapid development of new economic activities. With its Blue Growth strategy, the European Union seeks to strengthen the economy, increase jobs and income, and secure long-term wealth by "unlocking the potential of the ocean" [1]. Further development of ocean energy, aquaculture, coastal tourism, seabed mining, and marine biotechnology is foreseen. These activities compete with existing uses-e.g., shipping, fisheries, military purposes, and oil and gas-as they claim space in already intensively used European seas [2].

The marine ecosystem is a stressed ecosystem, under pressure from human activities [3-5]. The combination of new marine developments, competition for space, and ecosystems under pressure calls for effective use of marine space to avoid competing claims [6]. This can include the development of "multi-use platforms at sea" (MUPS), in which different marine activities are combined in a certain marine area $[7,8]$.

MUPS have already been of interest to researchers and there is literature available on diverse aspects of MUPS. The technical design of combinations is discussed, often with a focus on wind turbines and aquaculture $[9,10]$ or wave and wind energy $[11,12]$. Social scientific research analyzed social acceptance by wind-park operators, fishermen, and the like [13,14]. Economists have addressed the question of economic feasibility [15,16], while others have focused on planning issues [17] and identification of the proper sites for MUPS [18]. These multi-use platforms are difficult to realize as they come with a set of complex knowledge questions, challenges for governance, and issues of sustainability, and require cross-sectoral cooperation [13-15].

To address these complex questions-where technical, regulatory, financial, environmental, and socioeconomic aspects are intertwined-it is argued that stakeholders need to be involved in the planning and design of such MUPS to identify feasible and sustainable solutions [19]. Comparable pleas for stakeholder participation are made in the European directives on Marine Spatial Planning [20].

MERMAID is one of the research projects funded by the European Commission to investigate the concepts and the development of multi-use platforms. The general objective of MERMAID was to develop novel innovative multi-use platforms, and one of the specific objectives was to apply a participatory design process (PDP) involving stakeholders at the four case study sites. This paper presents and evaluates the PDP in the MERMAID project, the main question being if and how participation contributes to knowledge generation and learning, facilitating the design of multi-use platforms.

\section{Participatory Design}

\subsection{Theoretical Background}

As stated above, it has been argued that a participatory approach is required for handling complex problems that involve multiple sectors and stakeholders [19,21,22]. Wesselink et al. [21] formulate different objectives of participation:

- define the role and relevance of systematic (scientifically derived) and idiosyncratic (derived from experience and familiarity with local conditions) knowledge for making choices that affect large populations;

- find the most appropriate way to deal with uncertainty in environmental decision-making and set efficient and fair trade-offs between potential over- and under-protection in the face of uncertain outcomes;

- $\quad$ address concerns of the affected people and the public at large. 
The concept of participatory design gained ground in the late 1990s as designers acknowledged the need to design new systems with, rather than for, users. Participatory design studies have focused on a broad range of subjects such as health information systems [23], medical devices like wheelchairs [24], and agricultural landscapes [25]. Participatory design values the perspective, knowledge, skills, and involvement of different categories of end-users and other stakeholders [26,27].

Two principles underlie the participatory design approach. The principle of non-linear knowledge generation states that knowledge is developed in a complex, interactive process of co-production with a range of stakeholders involved [28,29]. The principle of social learning states that in the complex and uncertain search for sustainable designs one needs to learn from the interaction with other actors and each other's behavior [30].

Two processes are essential for creating mutual understanding: participation and reification. Participation implies that the members of the community get a sense of relationship, either based on conflict or harmony [31]. Reification means that the bits and pieces of knowledge that are learned are communicated in a concrete form (for example through reports, tables, and design wishes). Reification refers to actions within the community of practice like designing, naming, encoding, interpreting, and describing [31]. Based on this theoretical background, it is argued that a participatory design process can contribute to:

- Knowledge sharing across different sectors and stakeholders;

- Different stakeholder attitudes towards multi-use platforms converging into a shared attitude;

- Shared and concrete ideas for MUPS development;

- Identification of obstacles and opportunities.

If successful, the processes of participation and reification can contribute to improving the designs on multi-use platforms, possibly leading to successful innovation [32].

\subsection{The Participatory Design Process in MERMAID}

The PDP applied in MERMAID was an iterative process of scoping, envisioning, and learning, with the aim to develop a shared interpretation of MUPS. It consisted of three rounds, each with specific aims:

(1) Identification of the views and needs of selected stakeholders in the first round (reported in [33]);

(2) Discussion on preliminary MUPS design in the second round, bringing together selected stakeholders in a round table session (reported in [33]);

(3) Evaluation of the final design by means of interviews and a session with selected stakeholders in the third round (reported in [34]).

Six stakeholder categories were invited for the participatory design process: (1) governing bodies/policy makers; (2) end users of the MUPS e.g., energy companies and aquaculture entrepreneurs; (3) suppliers of the MUPS such as cable companies and construction businesses; (4) representatives of other offshore activities such as fisheries, shipping, and mining sectors; (5) discourse community, including e.g., (environmental) NGOs, local citizens; and (6) universities and research institutes.

Typically, energy companies, fisheries, universities, and research institutes were "internal" stakeholders in the sense that they were part of the MERMAID project, whereas governing bodies, suppliers, and the discourse community were "external" stakeholders, i.e., not part of the project. However, this differed for each site and a complete overview of the stakeholders can be found in [33-35]). Each site had a site manager within the MERMAID project who was a key actor in the three-step process, being responsible for organizing the participatory design process.

\section{Methodology for Evaluation}

To assess whether or not the participatory process delivered the benefits foreseen, the process was evaluated with the site managers-responsible for the organization of the process-and the participating stakeholders. The evaluation in this paper does not cover all aspects of group discussions and stakeholder involvement (e.g., did all participants have an equal chance to communicate their 
views, the importance of a professional facilitator, the importance of preparations of interactions and information material). Instead, the evaluation of the PDP is carried out with a focus on learning from the participatory design of MUPS. The evaluation of the participatory design process reported in this article draws upon two sources of information.

\subsection{Interviews with Site Managers}

After the first and second steps, interviews were conducted with the site managers involved. These interviews were conducted face-to-face or by Skype. A semi-structured questionnaire was used to enable site managers to focus on the issues they considered most important (see Appendix A for the questionnaires). A report on each of the interviews was written and sent to the interviewee for comments.

\subsection{Questionnaire to Stakeholders}

After each of the three steps, the internal and external stakeholders participating in the PDP were asked to fill in a questionnaire containing four short questions about stakeholders' attitudes with regard to future realization of MUPS. The hypothesis was that it would be possible to investigate whether any learning had been obtained by the stakeholders participating in the process by investigating: (1) if the stakeholders participating in the PDP changed their attitude over the course of the process as new knowledge became available; and (2) if the participating stakeholders would be more similar in their attitudes over the course of the process. The four questions were:

(1) What is the chance that multi-use offshore platforms will be in use in your region within five years? (please answer in \%)

(2) When will we see multi-use offshore platform in your region?

(3) How great do you estimate the chances are that your organization will play a role in it? (please answer in \%)

(4) Will your organization play a role in the multi-use offshore platforms? If so, what role?

Replies to Questions (1)-(3) from each site were analyzed with regard to changes between the rounds of the PDP, and with regard to the variability of the replies.

\section{The Four Sites and the Design Based on the PDP}

The MERMAID project focused on four case study sites representative for European waters, each with local challenges. The case studies differ not only with respect to physical aspects, but also with respect to marine spatial planning, current planning of offshore wind development, aquaculture activities, and governance. The involvement of stakeholders also differed: at some sites several stakeholders were part of the MERMAID project and had resources to join the PDP (e.g., the Baltic site), whereas in other cases there were no local project partners that were also stakeholders (e.g., the Mediterranean site).

There are large differences in the site-specific conditions-both in ecological status and potential for multi-use combinations, described in [35]. The sites differed and the PDP resulted in four different designs for multi-use platforms at sea. The outcome of the design process, for which stakeholders were present and in which stages of the PDP and how the participating stakeholders' concerns were taken into account, is described in greater detail in [33,34]. Below, a brief summary of the sites, the discussions, and the final designs is provided.

\subsection{The North Sea Site}

The North Sea site is a typical area with high morphological activity with focus on a location in Dutch waters where an offshore wind park Gemini is planned [36]. Stakeholders who had a relation with this area-for current and potential future uses-were identified and the following stakeholders participated in the PDP: offshore wind farm developers, seaweed and shellfish aquaculture 
fisheries, regulators and policy makers, offshore construction companies, companies interested in the end-product of the MUPs, and NGOs. In collaboration with the stakeholders, offshore wind parks combined with seaweed and mussel aquaculture was identified as the most promising conceptual multi-use design. The final design did not fully integrate the aquaculture structures inside the wind farm, but instead in the areas just outside of and in between the wind farms [34].

The wind energy developers were very clear regarding the conditions for design: multi-use should not cause any hindrances for wind turbines or obstacles for operation and maintenance activities. These developers in general strongly focus on avoiding or mitigating risks where external interference is seen as an additional risk, i.e., indirectly increasing investments costs. Costs for off-shore wind energy parks are already high and rely on subsidies to make viable business cases. The priority for wind producers and governments is to keep costs low. More willingness to cooperate in terms of multi-use is identified in wind park owners with more and longer operational experience. Sharing infrastructure among energy producers and aquaculture producers (and others) to reduce operational and maintenance costs is crucial for realizing MUPS.

Many of the participating stakeholders could see benefits in participating in a MUPS [34] e.g., with regard to more efficient use of space and functional synergies. The idea of MUPS was not new to stakeholders and their discussion focused on optimization with regard to sharing infrastructures to reduce O\&M costs and create win-win solutions. To increase employment and support the fisheries sector, their vessels, possibly redesigned, becoming part of an infrastructure was seen as important to consider. The biggest challenge for the North Sea site was to find solutions that could be profitable for all stakeholders, including the risks and extra insurance costs. In order to find investors, the license procedure needs to be aligned for multi-use, i.e., faster than today, and uncertainties need to be minimized.

\subsection{The Mediterranean Site}

The Mediterranean case represents a typical sheltered deep-water site with a focus on Italian waters, in the area off the Venetian coast. Offshore energy generation is currently not foreseen in this area. Stakeholders invited to the PDP included the energy sector, aquaculture, policy-makers, and environmental authorities [33,34]. The final design of a MUPS for the Mediterranean site includes grid-connected wind turbines combined with fish farming. In the MUPS layout the fish farm is placed in the space between the wind turbines [34].

Stakeholders were mostly interested in wave energy at the start; however, the wave energy option was eventually dismissed. The reason was the high costs of installation and operation, and greater occupied marine space to achieve a similar energy production with respect to wind turbines. On the other hand, the main reason for stakeholders to oppose wind energy was the fear of visibility issues from the coast and this concern of the stakeholders was taken into consideration during the PDP. The designers changed the MUPS location from $12 \mathrm{~km}$ to $27 \mathrm{~km}$ offshore. At this distance, the wind turbines are not visible from the coast anymore. The change in focus towards wind energy took place at a later stage of the PDP, when it was no longer possible to involve the wind energy stakeholders.

Stakeholders also opposed new aquaculture farms in the MUPS because they were afraid of competition with the already existing coastal aquaculture [34]. Despite this fear of competition, the MERMAID design team decided not to limit the design by this argument, which essentially was a plea for keeping a monopoly on the coastal aquaculture. Aquaculture was considered and included in the proposed MUPS design, since it is an activity that can be combined with the other uses. An additional supporting argument for including aquaculture in the proposed MUPS design was the existence and vicinity of a market for aquaculture products.

\subsection{The Atlantic Site}

In the Atlantic case, the focus was in Spanish waters on the Cantabrian offshore areas, a typical deep water site. The metocean conditions at this site are typical for an exposed area: harsh conditions 
leading to high technical demands. Offshore wind development is not foreseen in the area but there is experimentation on wave energy generation. The invited stakeholders included offshore energy sector, aquaculture, suppliers to the offshore industry, as well as NGOs and scientists. The final design included a combination of floating offshore wind turbines and wave energy generators [34].

Stakeholders stressed the importance of selecting a site where conflicts with other interests are minimal, e.g., a MUPS should be sufficiently far away from the coast and not cause negative impacts on the local fishing community. MUPS were considered to be able to provide revenues to both the local fishing community and local businesses. The importance of including marine renewable energy technology in the MUPS design and the benefits of this sector in the area of Cantabria were agreed upon.

During the round table meeting, the aquaculture sector showed interest in the development of MUPS, since they can make offshore aquaculture economically more attractive. However, after discussions with all the stakeholders, aquaculture was deemed very difficult technically.

The discussion identified the need for cooperation between stakeholders for accurate MUPS design. Some respondents provided examples to illustrate its importance: technically well-designed projects can still run into problems. Economic issues were also identified as the link to local communities as MUPS development may lead to the creation of new jobs in the area [34].

\subsection{The Baltic Site}

The Baltic case study, the Kriegers Flak in Danish waters, is representative of a typical estuarine area. Offshore wind energy is already an established business in this area and further development of the Kriegers Flak area is foreseen. Participants in the PDP included potential entrepreneurs to participate in the development of a multi-use platform, as well as governing bodies and the shipping authorities. Also, NGOs representing societal values and scientists participated. The design is a combination of wind turbines and off-shore aquaculture by floating fish-cages with trout/salmon production [34]. This combination is interesting given the large-scale development of offshore wind - with subsequent spatial claims and the critical attitude towards nearshore aquaculture.

The stakeholders put forward social aspects with regard to the visibility from shore of wind turbines. However, the design and location are such that, depending on the weather conditions, the wind turbines will seldom be visible. The entire wind park area should ideally be designated a cable protection area, and possibly the shipping lines that today pass Kriegers Flak need to be altered. Stakeholders discussed technical aspects for design such as maintenance and monitoring, anchoring and transport, and associated risks. A technical risk assessment of the MUPS is important and guidelines and rules to minimize risks must be developed to ensure the safety of people, vessels, cages, and wind turbines. In Denmark, the public image of wind turbines is positive while offshore aquaculture is more critically scrutinized due to its environmental effects. The stakeholders pointed out that there should be no negative effects on ecological conditions, and that the artificial reefs on the wind turbines' foundations should be protected as they have positive ecological effects.

\section{Evaluation of the Participatory Design Process}

\subsection{Site Managers' Reflections on the Participatory Design Process}

The interviews with the site managers were conducted to get insight into their experiences with and evaluation of the PDP. The following paragraphs describe the main findings from these interviews per case study. The outcome of the PDP is described in further detail in [33,34].

\subsubsection{The North Sea Site}

\section{On Participatory Processes}

After the second round, the site manager stated that the main benefits of a PDP were that "expert info, data, and insight from others will become available to the project. Also, stakeholders will feel like 
project owners and are therefore willing to cooperate". For the site manager, the main objective of the PDP was to meet stakeholders and avoid knowledge gaps related to potential additional uses of the wind park, including knowledge on market demand for such functions ("for adding seaweed and/or mussel cultivation to a wind farm") and "openness to innovations among stakeholders".

\section{On Stakeholders}

After the first round, the site manager stated that "it is important to interview a broad range of stakeholders". In general, it was believed that the right actors were involved in the process, even though some of the identified ones, e.g., tourism, were not interviewed.

After the second round, the site manager stated that not all stakeholders were willing to participate. The reason might be that many stakeholders were not giving priority to engage on a "conceptual and hypothetical setting" as MERMAID. Requests and incentives from the government to construct MUPS are suggested as possibilities to increase stakeholders' interest and participation.

The stakeholders who participated learned about ongoing research projects, became more aware of the possibilities of multi-use, and increased cooperation and networking. The site manager stated that "MERMAID enhanced the networking and made [networking] happen earlier". Additionally, stakeholders' attitudes towards MUPS changed: the site manager considered the more positive view on multi-use by the energy companies by the end of the PDP as an interesting change, as multi-use in offshore installations introduce even higher risks to the already high risks in an offshore environment. Energy companies are expecting this "to happen in the mid-term (3 10 years) when obliged by the regulators".

\section{On the Outcomes}

Regarding the outcomes of the first round, the site manager believes it increased stakeholders' understanding and acceptance of, and reduced objections to, MUPS. Contrary to initial expectations, there was positive feedback from the majority of stakeholders on the idea of multi-use, thus providing a "support for developing MUPS concepts". Additionally, it increased knowledge on the incentives of the stakeholders to participate in a MUPS, which "helps provides directions for optimizing designs". An example given by the site manager was that the interest of energy companies in increasing social acceptance contributes to their willingness to think about options for combining uses.

Concerning the second round, the site manager stated that it confirmed that the outcomes matched the expectations. Information gathered included specific possible uses to be combined with wind farming, and possible synergies of that. During the second round it was stated that MUPS should be located not too far away from the coast to avoid high transportation costs for the aquaculture sector, although that was not considered in the conceptual design for the North Sea case study since it was made for an actual wind park site. Moreover, some sectors are not ready to participate in a MUPS, specifically the shellfish industry in the Netherlands.

\section{Evaluation of the PDP}

In the first round, the site manager emphasized that the current MERMAID model for the PDP was valuable. The site manager considered that the current PDP design was not appropriate for all the sites, due to a difference of goals of the PDP ("brainstorming/getting to know each other vs. coming to agreement").

After the second round, the site manager stated that the format of the round table was appropriate for the North Sea site. As "a successful round table is dependent on the input of the participants", one needs to gather the appropriate stakeholders. Still, after the second round the site manager suggested that improvement of the participatory process might be achieved by more intense collaboration with stakeholders, rather than merely asking them to participate. 


\subsubsection{The Mediterranean Site}

Less material is available for evaluating the PDP in the Mediterranean case, as no interviews were carried out after the second round.

\section{On Participatory Processes}

The evaluation of the first round showed that the PDP was well accepted by the stakeholders, all of whom seemed to be involved and to understand the problem quite well.

\section{On Stakeholders}

There was a good attendance rate by those stakeholders that were invited for the first round (15 out of 17). However, there was a concern that they were not willing, or able, to look outside their own responsibility or expertise. In this case, it was particularly striking that stakeholders were concerned about their role in the participatory process-and whether or not they could justly represent the organization they worked for. Some stakeholders didn't answer some questions with the motivation that it was "not a goal of my institution". The site manager stated that this could be a familiar problem when dealing with multidisciplinary issues.

\section{On the Outcomes}

Although several stakeholders attended the first meeting, the site manager was not directly able to use the input from stakeholders in the first round as the designing procedure was not set up before the meeting.

The case study site is characterized as not particularly suitable for one specific technology or sector. Although some ocean energy generation is possible, the site lacks both beneficial wave and wind conditions. Subsequently, this case study experienced a longer discussion between stakeholders on which were the right functions to combine. In this discussion, an exchange of knowledge and ideas took place; for example, wave and wind engineers exchanged ideas, and the engineers obtained insights from the ecologist about the environmental impact of alternative structures.

The evaluation of the final design suffered from lack of interest in MUPS by the private sector. The first meeting highlighted that MERMAID was a research project, aiming at specifying a scientific methodology to be followed in MUPS design. Since the site was considered problematic, with small potential in terms of energy (both wind and wave) and a poor outlook in terms of environmental impact, many private investors dropped out of the process. Public agencies, however, kept attending.

\section{Evaluation of the PDP}

The site manager emphasized the need to show stakeholders how they can contribute to the design process, i.e., the importance of feedback to them, after the first round. For this site, it took quite some time before getting back to stakeholders a second time. Because several stakeholders dropped out after the first round, the design process changed in character; it became a process in which engineers (partners in MERMAID) interacted with a critical "audience" of policy-makers, NGOs, and other offshore sectors. The stakeholders were not involved in discussions on ecosystems, even though environmental aspects and metocean conditions were discussed. During the process, engineers obtained insights from stakeholders about current and potential obstacles to alternative locations. From fishermen, the engineers obtained insights about requirements for working offshore.

\subsubsection{The Atlantic Site}

\section{On Participatory Processes}

After the first round, the site manager stated he "had expected more enthusiasm about MUPS". However, over time, the process became a more fruitful experience: the exchange of ideas and 
discussions mutually enriched individual knowledge, and a clear view of the synergies and mutual restrictions emerged. The format of the round table was suitable for a process of collective learning as the stakeholders became aware of unexpected issues in the project perceived by others and of eventual improvements that could be obtained from others.

\section{On Stakeholders}

The group of participating stakeholders differed in the first and second rounds. Evaluating the first round, the site manager argued that additional stakeholders needed to be involved. In the second round, all major stakeholders were involved, although small and medium-sized enterprises were underrepresented.

\section{On the Outcomes}

The PDP incorporated the ecosystem specific conditions since the local particularities were considered from the very beginning. Based on them, the PDP led to a better identification of obstacles and opportunities. As a result of the discussions, mutual restrictions and exigencies were identified and an accurate MUPS design strategy could be carried out.

The impact of human activities on the biological substrate was a topic of joint analysis. The combined effects of anchoring, birds, and fishing attracted by aquaculture, food waste, and organic residuals, and the biodiversity effects of escaping fish and energy devices' interaction (noise and blades) were identified as the design basis of the MUPS. The importance of suitable business models for new marine activities was also pointed out and a relevant output of the activity. Another output from the process was an assessment of the compatibility among activities and the selection of the best candidates for MUPS in the Atlantic basin. A set of draft MUPS designs was subject to discussion, and ranking and commenting on the proposals substantially enriched the final design. Therefore, the site manager concluded that a convergence of ideas was achieved and some particular ideas have been considered during the later design phase.

\section{Evaluation of the PDP}

The site manager evaluated the PDP positively. After initial skepticism, noting that he had never been involved in this kind of design before-both rounds were evaluated positively. The first meeting changed his mind about the value of the process, showing that people are not willing to participate without information; "If they are to participate in the design and realization of MUPS, you need to send them information and involve them".

The site manager recognized the value of the PDP: "you have to involve the people in your solution". The PDP can help with understanding people's main concerns and uses that as a strength in the design since the concerns of the representatives are known. The main improvement for the future lies in convincing other stakeholders to participate: "The participation of the people can be improved".

\subsubsection{The Baltic Site}

\section{On Participatory Processes}

During the first round, the site manager stated that since the PDP contributes to the design, it is useful. For the second round, the site manager stated that the main objective for the PDP for the Baltic case was to ensure a qualified design of the MUPS, but also to provide a check of the project's logic and to make it possible to explain to outside parties. The benefits of the participatory process in general were seen as ensuring involvement and acceptance from stakeholders, and finding pitfalls in the project.

\section{On Stakeholders}

Already after the first round, the site manager stated that a broader representation of stakeholders would have been preferred. Many more were invited, but the reasons for them not showing up 
were not clear. After the second round, complementing the physical meetings with e-mails was proposed, to reach those stakeholders that did not have time to attend physical meetings, and thus get broader representation.

With regard to whether the stakeholders have influenced and/or learned from each other, the site manager stated that they indeed had influenced each other in the discussions. The example that was given was a discussion on risks. One of the participants had a concern that was discussed and the other participants learned how risks should be a part of the design. The site manager also stated that there had been a change in the stakeholders' attitudes towards MUPS in the sense that everybody now is more informed and realizes how complex the issue of a MUPS is. However, the site manager was not certain whether there were other activities outside MERMAID that could have contributed to this change in attitudes, and there was uncertainty about whether there was a difference in attitudes among internal and external stakeholders.

Not all groups of stakeholders have actively become involved. During round 2, the governing bodies/regulators/policy makers were missing, as well as suppliers of MUPS. Also the construction companies were missing in the process, apparently mostly due to commercial and competitive reasons. The lack of involvement of these bodies might potentially mean that not all obstacles are identified.

The participating scientists have gathered knowledge for the feasibility of a MUPS at Kriegers Flak. There is a high degree of knowledge about the site and the MUPS concept; however, alternative ways to develop a MUP need to be shared and discussed. To start with, there must be a combination of two users, to be built on further from there later, or to open up from the start for more combinations. This is also related to the willingness to invest and participate: it is crucial to think about the business model for MUPS and to learn about this in the network.

\section{On the Outcomes}

The site manager stated that it was used for a preliminary design. For the second round (the round table), the site manager hoped to get opinions from the stakeholders on the project draft they were converging on, and to get a project check: all important things were on the table. This was fulfilled, and there were a lot of technical issues raised (risk (important), cabling, navigation issues, separate spatial use, maintenance), which was all new input. The results from the second round influenced the design of the MUPS to a great extent, and several changes were made to the conceptual design after the second meeting.

All in all, after the third round it was stated that the PDP had initiated a dialogue with stakeholders about MUPS. The Baltic case study benefited from the fact that many relevant stakeholders were involved as active partners in the MERMAID project and that the convergence of ideas was easily communicated with the scientists. So within the project this convergence was successful. As a result, there was a clear setup available for a MUPS at Kriegers Flak. Given the divergent public images on the environmental issues and risks concerning offshore wind energy and aquaculture, the stakeholders found it important to involve society in the development of MUPS to promote the concept. Although this is partially covered in the Environmental Impact Assessment, this legal obligation alone is insufficient to bridge the gap between different stakeholders.

The financial assessments [37] suggest that no significant cost reductions can be realized when combining functions. However, it should be kept in mind that neither possible cost reduction scenarios nor possible arrangements and contracts were analyzed. In the future, these aspects should be analyzed in more detail. A benefit is expected for fish farmers if they join up with the wind sector, but the project did not succeed in showing the wind sector financial benefits from joining up with aquaculture. One important synergy identified is the more efficient use of limited ocean space when combining the two activities. 


\section{Evaluation of the PDP}

The site managers were also asked to evaluate the PDP, and in the first round, the site manager for the Baltic case suggested the process be much more focused, especially on the technical parts in the PDP. This opinion was still valid after the second round. Some suggestions to improve the PDP were to consider stakeholders' time resources and use e-mail as an addition to short meetings. However, the site manager also recognized the fact that the research project is not a "real" project, which may influence how stakeholder prioritize and allocate their time. Another lesson learned was to present a preliminary design to stakeholders such that the discussion becomes much more focused.

\subsection{Stakeholders' Perception of the Realization of MUPS}

This section presents the results of the short questionnaire that was sent out to all stakeholders participating in the PDP. The response rate to the questionnaire differed greatly between sites and over time. If the questionnaire was handed out in immediate connection with a physical interaction step of the PDP, there was up to a $100 \%$ response rate. However, if the questionnaire was sent out afterwards, e.g., when an interaction step was not physical, via e-mails, the response rate was in general lower, between $20 \%$ and $50 \%$. Furthermore, results from the Mediterranean site are missing to a great extent because of both a low response rate and few useable answers (if stakeholders returned the questionnaire, they often gave only text as an answer, thus not providing as was requested).

Overall, 68 respondents filled in the short questionnaire. However, all the stakeholders involved in the three steps are not identical throughout the PDP, thus the answers do not reflect the attitudes of the same stakeholders during the PDP. In fact, 53 stakeholders only filled in the questionnaire once. Twelve stakeholders answered the questionnaire twice, and only two participants did this three times (see Table 1).

Table 1. Overview of response ratios for the different sites.

\begin{tabular}{|c|c|c|c|c|c|c|}
\hline & & Total & Atlantic & Mediterranean & North Sea & Baltic \\
\hline \multirow{4}{*}{ Number of respondents } & Total & 68 & 17 & 16 & 24 & 11 \\
\hline & 1st round & 32 & 8 & 14 & 8 & 2 \\
\hline & 2 nd round & 25 & 9 & 1 & 11 & 4 \\
\hline & 3rd round & 26 & 5 & 1 & 12 & 8 \\
\hline \multirow{4}{*}{$\begin{array}{l}\text { Number of respondents } \\
\text { to only one of the rounds }\end{array}$} & Total & 54 & 13 & 15 & 18 & 8 \\
\hline & 1st round & 25 & 6 & 13 & 4 & 2 \\
\hline & 2 nd round & 16 & 6 & 1 & 8 & 1 \\
\hline & 3 rd round & 13 & 1 & 1 & 6 & 5 \\
\hline \multirow{4}{*}{$\begin{array}{l}\text { Number of respondents } \\
\text { to only two of the rounds }\end{array}$} & Total & 12 & 3 & 1 & 5 & 3 \\
\hline & Rounds 1 \& 2 & 0 & 0 & 0 & 0 & 0 \\
\hline & Rounds 2 \& 3 & 7 & 2 & 0 & 2 & 3 \\
\hline & Rounds 1 \& 3 & 5 & 1 & 1 & 3 & 0 \\
\hline $\begin{array}{l}\text { Number of respondents } \\
\text { to all three rounds }\end{array}$ & Total & 2 & 1 & 0 & 1 & 0 \\
\hline
\end{tabular}

Figure 1 shows the average (arithmetic mean) value of replies to Questions 1 to 3 (left side), and the variability of the replies (right side), measured as the coefficient of variation (CV), i.e., the standard deviation divided by the arithmetic mean. The sample size for each question, site, and round is shown in Table 1. The presentation of results from the Mediterranean is confined to single dots in some of the diagrams. 


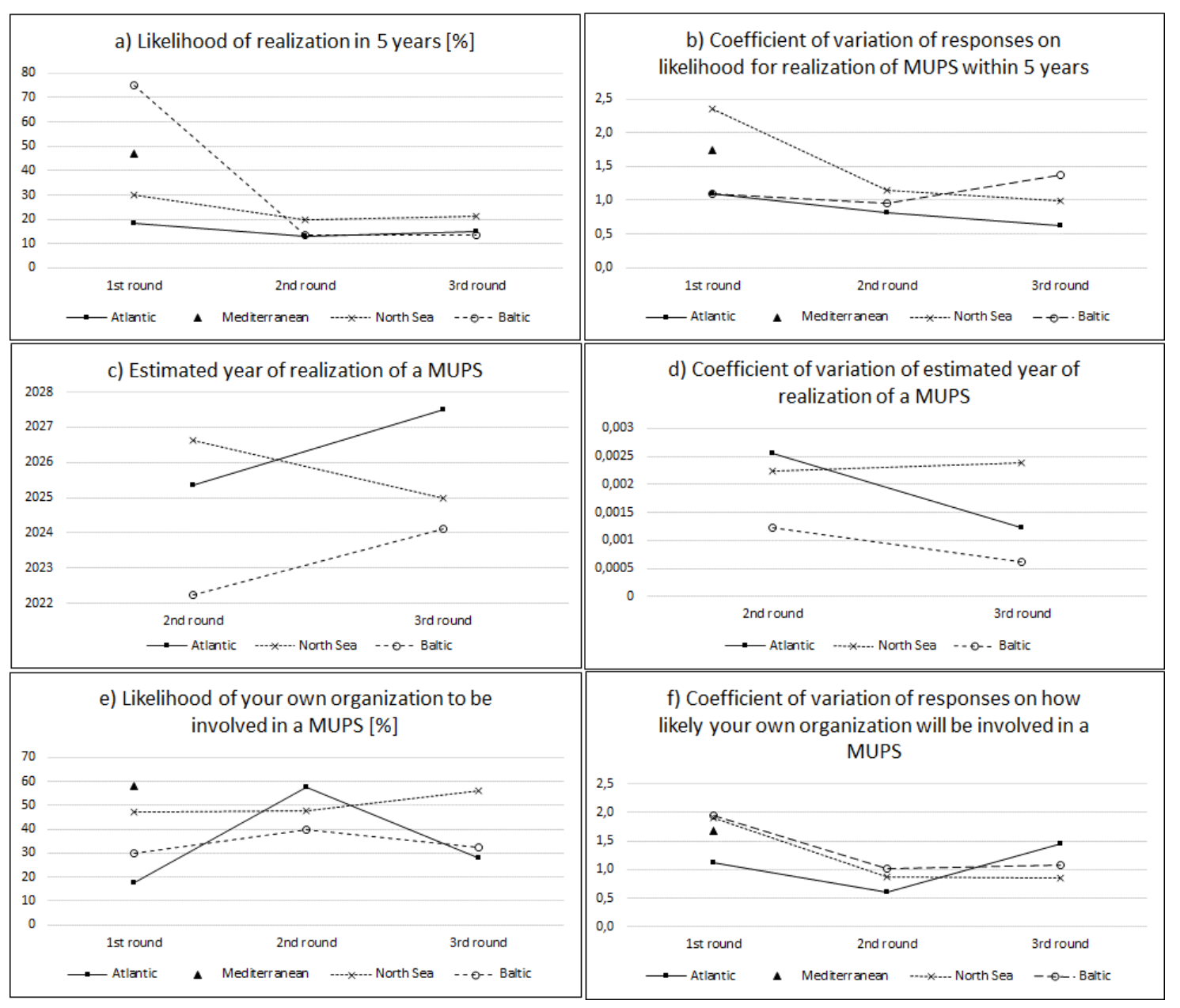

Figure 1. Diagram (a) show the replies for each site as an average (arithmetic mean) regarding the likelihood in \% that a MUPS will be realized in five years; Diagram (b) shows the corresponding coefficients of variation for the responses for each site; Diagram (c) shows the replies for each site as an average (arithmetic mean) regarding when a MUPS will be realized (estimated year); Diagram (d) shows the corresponding coefficients of variation for the responses for each site; Diagram (e) shows the replies for each site as an average (arithmetic mean) regarding the likelihood in \% of the respondents' own organizations being involved in a MUPS; Diagram (f) shows the corresponding coefficients of variation for the responses for each site. The number of responses to each question and round varies from 2 to 14; see details in Table 1.

In general, the stakeholders estimated the chances of MUPS being realized in five years' time to be higher in round 1 compared to round 2 (Figure 1a). For all sites, the average estimated likelihood was lowest after the second round but the results of the second and third rounds did not differ much. The results between the sites showed a more similar estimated likelihood after the second and third round, whereas during the first round, answers differed widely between the case studies, from an average of $75 \%$ in the Baltic to $19 \%$ in the Atlantic. After the third round, the estimated likelihood ranged between $15 \%$ and $23 \%$. Figure $1 \mathrm{~b}$ shows that the variability of the replies for each site decreases for each round, except for the Baltic site. For the Baltic site, the CV increases from the second to the third round.

Stakeholders were also asked when (i.e., in which year) MUPS are likely to be realized (Figure 1c,d). For the Baltic site and the Atlantic site, the stakeholders estimated a longer time horizon from the second to the third round (from 2022 to 2024, and from 2025 to 2027.5, respectively). For the North Sea, the replies of the stakeholders showed the opposite: the estimated time horizon decreased from 2027 
to 2025 in the third round. With regard to the variability of the replies, the CV decreased for the Baltic and the Atlantic cases, whereas there was a slight increase in CV for the North Sea site.

In the third question, stakeholders were asked about the chance in $\%$ that they would play a role in the development of MUPS in the region (Figure 1e,f). For the Baltic and the Atlantic site, the estimated $\%$ is highest in the second round, whereas for the North Sea site it is steadily increasing. Looking at the $\mathrm{CV}$, the replies are more and more similar over the rounds except for the Atlantic case, where the CV is highest after the third round.

\section{Discussion}

\subsection{Is Knowledge Shared across Different Sectors and Stakeholders?}

The outcome of knowledge sharing differed between sites. For the Baltic site, the relevant different sectors were partners in MERMAID and had the resources and the willingness to actively collaborate on all the necessary different assessments (technical, financial, legal, environmental, social, and economic). The PDP had the function of bringing different actors together. It is concluded that this approach of involving stakeholders worked well in terms of arriving at concrete suggestions for a MUPS. To a lesser extent, the same also goes for the North Sea.

For the Mediterranean and Atlantic sites, MUPS were less tangible at the start of the project. Since the idea of combining function was hardly known to stakeholders, the participatory process had a different function. It was aimed at getting different sectors acquainted with each other and introducing the concept of MUPS. Maritime, fish aquaculture, and energy stakeholders effectively showed their interest and concern so that the compatibility areas for the combined activities were made visible for the potential location decisions.

\subsection{Are Ideas Channeled into a Shared Understanding on the Most Promising Technological Trajectory?}

In all four sites, the process led to the identification of the most promising technological trajectory, in the context of climate and metocean conditions. Between the cases, there are differences between the more "realistic on short-term" cases in the Baltic and, to some extent, the North Sea and blue-sky thinking in the Atlantic and Mediterranean.

Baltic (Kriegers Flak) and North Sea (Gemini) are realistic cases, at sites already selected for the construction of offshore wind parks. Particularly in the Baltic site, many relevant stakeholders were partners in MERMAID. Hence, this case study started off with an existing network of stakeholders from science and industry that worked on refining a technological trajectory already chosen.

In the cases of the Atlantic and Mediterranean, different technological trajectories were envisioned and discussed before selecting the most promising option. This related both to aquaculture and different ocean energy technologies.

\subsection{Does the PDP Result in Shared and Concrete Ideas for MUPS Development?}

MERMAID resulted in designs for MUPS at the four sites. Stakeholder concerns are addressed in these designs; the participatory design provided an opportunity to give visibility to an informal community of interests acting as facilitator of consensus among the agents. For many stakeholders, the abstract concept of MUPS has materialized in concrete design for MUPS.

What was vague at the start of the design process has now become more tangible. The visual designs [25] became tools to present and discuss the abstract notion of combining functions at sea. For many, this concretization came with the recognition that MUPS are more difficult to create than first envisioned (see Figure 1a,b).

\subsection{Does the PDP Identify Obstacles and Opportunities?}

Stakeholders have identified several barriers, e.g., leading to redesigning of the MUPS in the Atlantic and Mediterranean sites. Technical barriers were frequently discussed and were addressed in 
the design and engineering of MUPS. The social barriers to MUPS are equally important, according to site managers, but less easily addressed. The process did not always succeed in closing the differences between different sectors. One reason is the financial barrier; there are still too many unknowns and/or uncertainties about the financial prospects of MUPS. Another relevant issue is the risk due to multi-use or sharing of space, which increases the already high risks of offshore use. Businesses are not motivated to participate in the development of MUPS as they face many unknown (institutional) risks and have limited expectations on positive economic gains. Figure $1 \mathrm{a}, \mathrm{b}$ also indicates that stakeholders got a more realistic view of the challenges in developing MUPS.

The PDP has succeeded in identifying obstacles for MUPS development in all four case studies but was less successful in clarifying the potential benefits associated with MUPS. The benefits are often rather general and include provision of food, efficient use of space, and potential-yet difficult to estimate-functional synergies. It proved hard to pinpoint why a MUPS is interesting for a wind park operator or what wave energy developers gain from a combination of functions.

\section{Conclusions and Recommendations}

\subsection{Conclusions}

Surveying the four case studies, we conclude that the participatory design process has made a valuable contribution to the design of the MUPS in the four study sites. In all cases, there has been an exchange of knowledge, interest, and at least a start in bringing different sectors together. A main remaining obstacle for MUPS to be realized, however, is the large uncertainties associated with potential technical and financial synergies across various functions.

The most valuable lesson derived from this research is that the PDP role will differ with each case and that consequently the selected approach should be tailored to the situation. In the Baltic site, a predefined group of MERMAID participants sought to discuss the feasibility of realizing a MUPS at a specific location. This is different from the Atlantic and Mediterranean sites, where the idea of MUPS was unknown beforehand and the process was aimed at bringing together stakeholders to explore the potential of MUPS at these locations. The North Sea site was in between; even though the site was predetermined, the stakeholders embarked on a process to better understand each other's needs in developing a MUPS at the specified location.

\subsection{Recommendations}

In order to facilitate upcoming processes for the development and implementation of offshore MUPS, a number of recommendations for a future participatory design approach are given. These could also be applicable to other types of project designs.

It is recommended to start with an initial assessment of the context. It is important to know the situation and conditions of the site under consideration-e.g., what technologies are possible. Based on this, identify the relevant stakeholders along with their roles, objectives, and resources. Following this, investigate which project phase applies to the proposed site, e.g., identifying a business case, exploring options to "add" functions to a planned development, or investigating the idea of MUPS from scratch.

Secondly, it is recommended to involve the relevant set of stakeholders for specific decisions. In early exploratory project phases, take stock of the differing views of the stakeholders. In a technical scoping phase, it makes sense to only involve a small group of relevant experts. In later project phases, stakeholders should be asked to suggest a few reasonably well-defined design options that are possible for the specific offshore multi-use platform.

Finally, shared knowledge and experience can contribute to more efficient and sustainable designs of offshore multi-use platforms. Acknowledging stakeholders' perspectives contributes to the surpassing of potential obstacles and allows for adjusting the design process as necessary. On the contrary, no dialogue or not considering stakeholders' point of view leads to the risk of inefficient processes, the need to repeat procedures, or even implementing sub-optimal solutions. 
Acknowledgments: This research was funded under the Seventh Framework Program, Theme [OCEAN.2011-1]. “Innovative Multi-purpose off-shore platforms: planning, design and operation" Grant Agreement no.: 288710. We thank all participants in the PDP for their contribution.

Author Contributions: This paper was compiled by Sander van den Burg, Jenny Norrman, Rita Garção, and Tore Söderqvist with input from all co-authors. All authors were involved in preparation of the round tables, interviews and/or analysis of outcomes. All authors read and approved the final manuscript.

Conflicts of Interest: The authors declare no conflict of interest.

\section{Abbreviations}

The following abbreviations are used in this manuscript:

$\begin{array}{ll}\text { NGO } & \text { non-governmental organization } \\ \text { MUPS } & \text { Multi-Use Platform at Sea } \\ \text { PDP } & \text { Participatory Design Process }\end{array}$

\section{Appendix A}

The following questions were asked after the first round:

- How do you value the current/proposed model for the participatory design process?

- In your opinion, are the right actors involved in the process?

- Are the varying stakeholder views properly represented in the findings?

- Do the results represent the local situations?

- How can you use the provided information in development of MUPS?

- What could be improved in the current model for the participatory design process in MERMAID?

After the second round the following questions were asked to the site managers:

\section{On participatory processes}

- In your opinion, what are the benefits of a participatory approach (participatory process is defined as a process in which stakeholders are involved in decision-making (in the broadest sense)) in general (not restricted to MERMAID)?

- What would you say is the main objective of the participatory process in MERMAID?

- What is your main objective for the participatory process as a site manager?

\section{On stakeholders}

- Was the selection, presence of, and format for involving stakeholders appropriate to reach the objectives (as discussed above)? If not, what were the weaknesses in the selection, presence, and format for involvement?

- Have the stakeholders influenced and/or learned from each other? If yes: How? Can you give an example?

- Since the start of MERMAID, have there been changes in the stakeholders' attitudes towards MUPS? If yes, what has changed?

- If there have been changes, do you think that MERMAID contributed to these changes? If yes, how? If not, what has been the main driving force for the changes?

- Is there a difference with regard to changes in attitudes between stakeholders that are MERMAID project participants and stakeholders that are not project participants?

On the outcomes of the round table (second round of participatory process)

- What information and results did you hope to gather from the second participatory round (the round table)?

- What information and lessons did the second participatory round (the round table) provide you with?

- How do the outcomes match the expected outcomes? 
- Did the results from the round table impact or influence the design of MUPS?

\section{Evaluation of the second round}

- Was the format for this round table appropriate to reach your objectives?

- About the following round table: do you have suggestions on the format for this round table?

- In your opinion, how can the participatory process be improved?

- If you were asked to formulate a lesson for future project developers out of the experiences with the participatory approach, what would it be?

\section{References}

1. Pinto, H.; Cruz, A.R.; Combe, C. Cooperation and the emergence of maritime clusters in the Atlantic: Analysis and implications of innovation and human capital for blue growth. Mar. Policy 2015, 57, 167-177. [CrossRef]

2. Jay, S.A. Built at sea: Marine management and the construction of marine spatial planning. Town Plan. Rev. 2010. [CrossRef]

3. Jacques, P.J. Are world fisheries a global panarchy? Mar. Policy 2015, 53, 165-170. [CrossRef]

4. Gall, S.C.; Thompson, R.C. The impact of debris on marine life. Mar. Pollut. Bull. 2015, 92, 170-179. [CrossRef] [PubMed]

5. Hastings, E.; Potts, T. Marine litter: Progress in developing an integrated policy approach in Scotland. Mar. Policy 2013, 42, 49-55. [CrossRef]

6. Ritchie, H. Understanding emerging discourses of Marine Spatial Planning in the UK. Land Use Policy 2014, 38, 666-675. [CrossRef]

7. Lacroix, D.; Pioch, S. The multi-use in wind farm projects: more conflicts or a win-win opportunity? Aquat. Living Resour. 2011, 24, 129-135. [CrossRef]

8. Buck, B.H.; Krause, G.; Michler-Cieluch, T.; Brenner, M.; Buchholz, C.M.; Busch, J.A.; Fisch, R.; Geisen, M.; Zielinski, O. Meeting the quest for spatial efficiency: Progress and prospects of extensive aquaculture within offshore wind farms. Helgol. Mar. Res. 2008, 62, 269-281. [CrossRef]

9. He, W. Jacket-Cage: Dual-Use the Jacket Foundation of Offshore Wind Turbine for Aquaculture Farming. Wind Eng. 2015, 39, 311-320. [CrossRef]

10. Buck, B.H.; Ebeling, M.W.; Michler-Cieluch, T. Mussel cultivation as a co-use in offshore wind farms: Potential and economic feasibility. Aquac. Econ. Manag. 2010, 14, 255-281. [CrossRef]

11. Pérez-Collazo, C.; Greaves, D.; Iglesias, G. A review of combined wave and offshore wind energy. Renew. Sustain. Energy Rev. 2015, 42, 141-153. [CrossRef]

12. Zanuttigh, B.; Angelelli, E.; Kortenhaus, A.; Koca, K.; Krontira, Y.; Koundouri, P. A methodology for multi-criteria design of multi-use offshore platforms for marine renewable energy harvesting. Renew. Energy 2016, 85, 1271-1289. [CrossRef]

13. Wever, L.; Krause, G.; Buck, B.H. Lessons from stakeholder dialogues on marine aquaculture in offshore wind farms: Perceived potentials, constraints and research gaps. Mar. Policy 2015, 51, 251-259. [CrossRef]

14. Hooper, T.; Ashley, M.; Austen, M. Perceptions of fishers and developers on the co-location of offshore wind farms and decapod fisheries in the UK. Mar. Policy 2015, 61, 16-22. [CrossRef]

15. Griffin, R.; Buck, B.H.; Krause, G. Private incentives for the emergence of co-production of offshore wind energy and mussel aquaculture. Aquaculture 2015, 436, 80-89. [CrossRef]

16. Van den Burg, S.W.K.; van Duijn, A.-P.; Bartelings, H.; van Krimpen, M.M.; Poelman, M. The economic feasibility of seaweed production in the North Sea. Aquac. Manag. Econ. 2016, in press.

17. Christie, N.; Smyth, K.; Barnes, R.; Elliot, M. Co-location of activities and designations: A means of solving or creating problems in marine spatial planning? Mar. Policy 2014, 43, 254-261. [CrossRef]

18. Benassai, G.; Mariani, P.; Stenberg, C.; Christoffersen, M. A Sustainability Index of potential co-location of offshore wind farms and open water aquaculture. Ocean Coast. Manag. 2014, 95, 213-218. [CrossRef]

19. Röckmann, C.; van Leeuwen, J.; Goldsborough, D.; Kraan, M.; Piet, G. The interaction triangle as a tool for understanding stakeholder interactions in marine ecosystem based management. Mar. Policy 2015, 52, 155-162. [CrossRef]

20. Pomeroy, R.; Douvere, F. The engagement of stakeholders in the marine spatial planning process. Mar. Policy 2008, 32, 816-822. [CrossRef] 
21. Wesselink, A.; Paavola, J.; Fritsch, O.; Renn, O. Rationales for public participation in environmental policy and governance: Practitioners' perspectives. Environ. Plan. A 2011, 43, 2688-2704. [CrossRef]

22. Berghöfer, A.; Wittmer, H.; Rauschmayer, F. Stakeholder participation in ecosystem-based approaches to fisheries management: A synthesis from European research projects. Mar. Policy 2008, 32, 243-253. [CrossRef]

23. Pilemalm, S.; Timpka, T. Third generation participatory design in health informatics-Making user participation applicable to large-scale information system projects. J. Biomed. Inform. 2008, 41, 327-339. [CrossRef] [PubMed]

24. Wilkinson, C.R.; de Angeli, A. Applying user centred and participatory design approaches to commercial product development. Design Stud. 2014, 35, 614-631. [CrossRef]

25. Murgue, C.; Therond, O.; Leenhardt, D. Toward integrated water and agricultural land management: Participatory design of agricultural landscapes. Land Use Policy 2015, 45, 52-63. [CrossRef]

26. Simonsen, J.; Robertson, T. Routledge International Handbook of Participatory Design; Routledge: London, UK, 2012.

27. Bjögvinsson, E.; Ehn, P.; Hillgren, P.A. Design things and design thinking: Contemporary participatory design challenges. Des. Issues 2012, 28, 101-116. [CrossRef]

28. Gibbons, M.; Limoges, C.; Nowotny, H.; Schwartzman, S.; Scott, P.; Trow, M. The New Production of Knowledge: The Dynamics of Science and Research in Contemporary Societies; SAGE: London, UK, 1994.

29. Rip, A. Fashions, lock-ins and the heterogeneity of knowledge production. In The Future of Knowledge Production in the Academy; Jacob, M., Hellstrom, T., Eds.; SRHE and Open University press: Buckingham, UK, 2000; pp. 28-39.

30. Bandura, A. Social Learning Theory. 2013. Available online: http://www.esludwig.com/uploads/2/6/1/0/ 26105457/bandura_sociallearningtheory.pdf (accessed on 25 December 2013).

31. Wenger, E. Communities of Practice, Learning, Meaning and Identity; Cambridge University Press: Cambridge, UK, 1999.

32. Nelson, R.; Winter, S. In search for a useful theory of innovation. Res. Policy 1977, 6, 36-76. [CrossRef]

33. Rasenberg, M.; Stuiver, M.; van den Burg, S.; Norrman, J.; Söderqvist, T. Stakeholder Views 2. 2014. Available online: http:/ / www.mermaidproject.eu/sharepoint/Documents/Deliverables/D2.3-Stakeholder-views-2-PU/ (accessed on 25 January 2016).

34. Röckmann, C.; Stuiver, M.; van den Burg, S.; Zanuttigh, B.; Zagonari, F.; Airoldi, L.; Angelelli, E.; Suffredini, R.; Franceschi, G.; Bellotti, G.; et al. Platform Solutions. 2015. Available online: http:/ / www.mermaidproject.eu/ sharepoint/Documents/Deliverables/D2.4-Platform-solutions-incl-Annexes_DLO/ (accessed on 25 January 2016).

35. Zanuttigh, B.; Schouten, J.J.; Guanche, R.; Petersen, O. Site Specific Conditions. 2013. Available online: http://www.mermaidproject.eu/sharepoint/Documents/Deliverables/D7.1-Site-SpecificConditions-PU/ (accessed on 25 January 2016).

36. Gemini Offshore Windpark. Available online: http://geminiwindpark.nl (accessed on 25 November 2015).

37. Giannouli, A. Socio-economic Analysis of Baltic site. 2015. Availabel online: www.mermaidproject.eu (accessed on 24 January 2016).

(C) 2016 by the authors; licensee MDPI, Basel, Switzerland. This article is an open access article distributed under the terms and conditions of the Creative Commons by Attribution (CC-BY) license (http://creativecommons.org/licenses/by/4.0/). 